\title{
STUDIES ON STRENGTH AND DEFORMATION BEHAVIOUR OF TWO-WAY NSC AND HSC SLABS UNDER SINGLE POINT LOADING
}

\author{
Arjun R P Reddy ${ }^{1}$, Nandeesh M S ${ }^{2}$, R Prabhakara ${ }^{3}$ \\ ${ }^{l}$ M.Tech Student in Civil Engineering, Department MSRIT, Bangalore \\ ${ }^{2}$ M.Tech Student in Civil Engineering Department MSRIT, Bangalore \\ ${ }^{3}$ Professor and Head of the Department of Civil Engineering, MSRIT, Bangalore
}

\begin{abstract}
In the present study the experimental investigations were carried out on two way slabs for simply supported condition. A total four slabs spanning over $940 \mathrm{~mm}$ with an effective depth of $74 \mathrm{~mm}$ were tested under a single point loading to understand the flexural behaviour of two way slabs. The effect of increase in grade of concrete and percentage of reinforcement were studied on the first crack load, ultimate load and on their corresponding deflections. The combined load deflection behaviour of slabs was plotted and arrived at Energy absorptions and ductility indices. The comparison of ultimate load to the Johanssen yield load was also carried out and the relevant conclusions were reported.
\end{abstract}

Keywords: Two Way Slabs, NSC, HSC, Johanssen Yield Load, Energy Absorption, Ductility

\section{INTRODUCTION}

Slabs are integral part of a structure and widely used structural members. In various situations slabs are subjected to vehicle collisions, rack falls, falling of materials during construction, accidental events in industries etc. which may cause distress in the member. The behaviour of slabs under these conditions is not similar to static loading. While designing slabs these aspects are not considered and hence the study on impact behaviour of slabs are essential to minimize these adverse effects. Understanding static behaviour of RC slabs and extrapolating this information in understanding the impact behaviour of slab is not logical. Use of high strength concrete (HSC) in the construction industry has increased in the recent years. The structural behaviour of HSC under static and impact load has to be understood before it is put into the practice. More investigations are available on the static behaviour of structural elements because of simplicity in the experimentation and timely completion of projects. Experimentations on Impact behaviour of structural elements requires sophisticated test setup and consumes more time, sometimes it will be very sensitive to the results obtained therefore the available literature are less. It has been observed in the recent years drop tests are becoming popular because of their simplicity and less consumption of time. It is possible to obtain peak acceleration, velocity profile, damping coefficient and acceleration decay from accelerometers used in the drop test.

\section{LITERATURE REVIEW}

RAKESH KUMAR SAHU et.al, [1] The present study was aimed to develop high strength concrete (HSC) mix design using locally available materials and Normal strength concrete (NSC) mix design. The functional formulas to determine the parameters for High strength concrete are obtained for water cement ratio, water content, FA content, CA content and cement content. Those equations are used to develop the mix designs for M50, M60 and M70. SUDARSANA RAO HUNCHATE et.al, [2] The authors have carried out investigations to give design mix for HPC by using silica fume and superplasticizers. Total six mixes were prepared by keeping w/c ratio 0.29 constant, varying silica fume percentage from which cubes and cylinders were casted. As the replacement increases the compressive strength increases up to optimum percentage and then decreases gradually. N BANTHIA et.al, [3] They have reported the general bending load versus load point deflection graphs were plotted for various specimens for both static and dynamic loading. The higher values of fracture energies obtained from the composites than the unreinforced matrix. The conventionally reinforced concrete with its strategically placed reinforcing bars was found to be most impact resistant of other concretes such as normal strength plain concrete, High strength concrete, normal strength polypropylene fibre reinforced concrete and normal strength steel fibre reinforced concrete.

ANDREAS ANDRESSON [4] The load carrying capacity of concrete slabs subjected to concentrated loads are studied considering both static and impact loads. The slabs failed in one-way flexure. The concrete fallout was more in the slabs with rebar mesh than the slabs with SFRC. The residual strength after the impact was sufficient to carry the static load of impact test. MICAEL INACIO, et.al, [5] An experimental research was conducted to investigate the punching behaviour of high strength concrete (HSC) flat slabs, presenting a compressive concrete strength of 130 MPa. All specimens exhibited a decrease of stiffness when the flexure cracks start to form and develop. Furthermore, before cracking, the stiffness of the HSC specimens was slightly higher than of the NSC specimen. The test results 
also showed a displacements decrease at failure with the increase of the longitudinal reinforcement ratio, while stiffness increased slightly. From the results obtained, and for this set of tests, it is possible to conclude that the use of HSC instead of NSC led to an increase up to $43 \%$ of the punching capacity. The increase of reinforcement ratio from $0.94 \%$ to $1.48 \%$ led to an increase of punching capacity of $12 \%$.

\section{OBJECTIVES}

- To obtain the workable mix proportions for NSC (Normal Strength Concrete) and HSC (High Strength Concrete) which satisfies strength criteria.

- To record the flexural behaviour of slabs under static loading.

- To analyse the static test results over the influencing parameters such as cracking load, ductility index, Energy absorption and failure criteria.

\section{MATERIALS AND MIX PROPORTIONS}

Characterisation of materials used in the present investigation has been carried out as per the standard procedure. The various materials used in the experimental work are Cement, fine aggregate, coarse aggregate, water, reinforcing steel and admixtures. Each of the material used in the experiment has been discussed in detail below.

- CEMENT - In the present work, Ordinary Portland Cement of 53 grade conforming to IS: $12269-2013$ has been used.

- FINE and COARSE AGGREGATES - The fine and coarse aggregates used was as per the specifications as per IS 383-1970.

- REINFORCING STEEL - The reinforcing steel was found to satisfy the specifications as per IS 1786: 2008.

- ADMIXTURE - The superplasticizer used in the present work is Master Glenium Sky 8233 which is commercially marketed by BASF Construction Chemicals (India) Private Limited is used for M70 concrete and Siri plast is used for M20 concrete.

- WATER - Potable water free from injurious salts for both mixing and curing is used as per IS 456:2000

\subsection{Mix Design Procedure}

There are many methods of mix design available for the Normal Strength Concrete (NSC) such as New British Method, IS method, ACI method, British method, Fineness modulus method, Maximum Density method, Road note No.4 method and minimum voids method. All these methods give a channelized procedure for proportioning the basic ingredients of the NSC. However, there is no single and channelized procedure available for HSC since there are many methods by which, one can get proportioning of HSC. Mix design procedure was formulated by combining the BIS method, ACI methods for concrete mix design and available literatures. This procedure was adopted as it gives the least cement requirement $\left(\mathrm{kg} / \mathrm{m}^{3}\right)$ for any particular mix compared to other methods. Also the charts and curves available

\subsection{Trial mixes}

NSC (M20) as per IS 10262:2009 and HSC (M70) as per R P et.al Mix Design

Table 1: Trial Mix design specifications for NSC and HSC

\begin{tabular}{|l|l|l|}
\hline Ingredient & NSC & HSC \\
\hline Cement $\left(\mathrm{kg} / \mathrm{m}^{3)}\right.$ & 405.00 & 500 \\
\hline Coarse Aggregate $\left(\mathrm{kg} / \mathrm{m}^{3}\right)$ & 904.40 & 714 \\
\hline Fine Aggregate $\left(\mathrm{kg} / \mathrm{m}^{3}\right)$ & 801.33 & 1000 \\
\hline Water $\left(\mathrm{kg} / \mathrm{m}^{3}\right)$ & 202.50 & 150 \\
\hline Superplasticizer $\left(\mathrm{kg} / \mathrm{m}^{3}\right)$ & - nil- & 7.47 \\
\hline Compressive Strength $(\mathrm{MPa})$ & 25.51 & 76.02 \\
\hline
\end{tabular}

\subsection{Specimen Casting}

The specimen casting was done to carry out the tests for studying the behaviour of slabs in static loading by varying the parameters such as grade of concrete, percentage of reinforcement and drop height. A total of 4 slabs were required for all these parameters to be effectively studied. The specimen naming was done in an efficient manner to identify the slabs with ease. The table 2 provides the various slab identifications and the details of the specimen.

Table 2: Specimen characterization and naming

\begin{tabular}{|c|c|c|c|c|}
\hline $\begin{array}{c}\text { S1 } \\
\text { no }\end{array}$ & Slab ID & $\begin{array}{c}\text { Concrete } \\
\text { Grade }\end{array}$ & \multicolumn{2}{|c|}{ Reinforcement details } \\
\hline 1 & M20/PT1 & M20 & PT1 $=0.34 \%$ & $8 \mathrm{~mm} @ 240 \mathrm{C} / \mathrm{C}$ \\
\hline 2 & M20/PT2 & M20 & PT2 $=0.79 \%$ & $12 \mathrm{~mm} @ 240 \mathrm{C} / \mathrm{C}$ \\
\hline 3 & M70/PT1 & M70 & PT1 $=0.34 \%$ & $8 \mathrm{~mm} @ 240 \mathrm{C} / \mathrm{C}$ \\
\hline 4 & M70/PT2 & M70 & PT2 $=0.79 \%$ & $12 \mathrm{~mm} @ 240 \mathrm{C} / \mathrm{C}$ \\
\hline
\end{tabular}

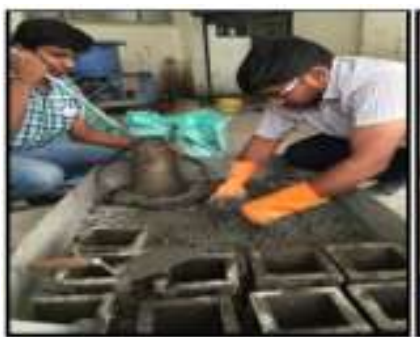

Fig.1 Mixing for Trial Mix

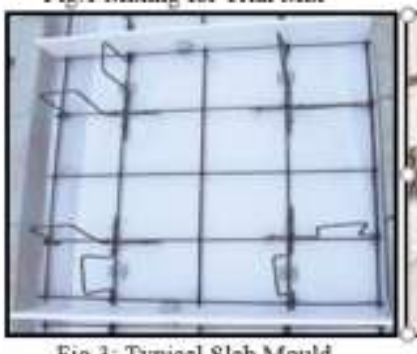

Fig.3: Typical Slab Mould

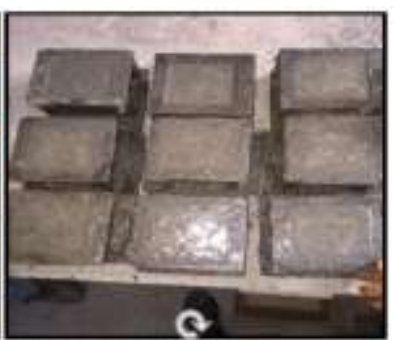
Fig, 2: Cubes Cast for Mix testing (1)

Fig. 4: Casting of Slabs 


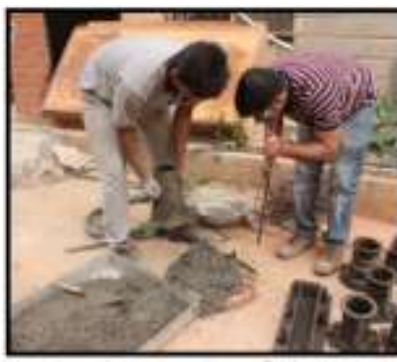

Fig. 5 Testing of Shump

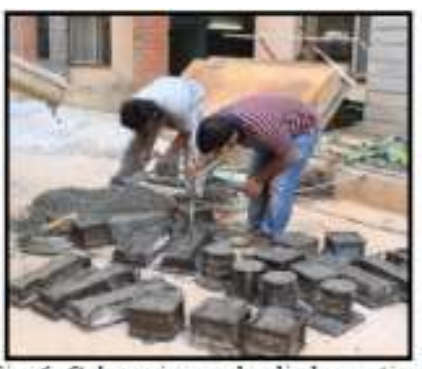

Fig. 6: Cube, prism and cylinder casting

\section{EXPERIMENTAL SETUP}

The static test setup was as shown in the figure. The LVDT was used to measure the deflections and data acquisition system was used to capture the load deflection data. The rate of loading was $0.5 \mathrm{kN} / \mathrm{second}$.

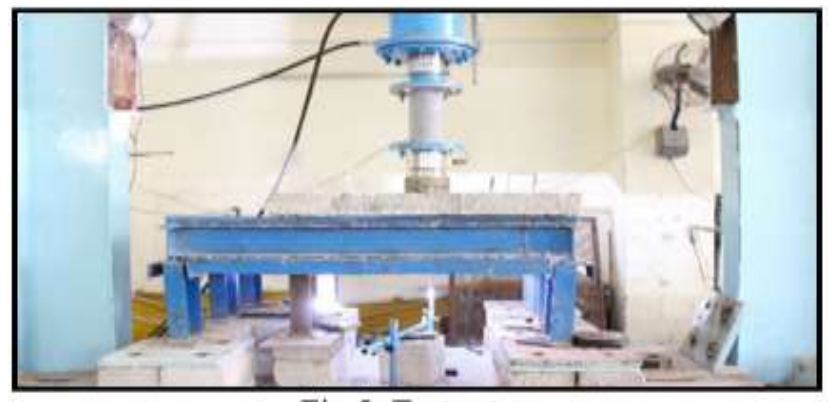

Fig.5: Test setup

\section{RESULTS}

\subsection{First Crack Load and Ultimate Load}

From the experimental investigation conducted in the laboratory the first crack load and the ultimate load with their corresponding deflections were tabulated in the table 3 .

Table:3 First Crack load and Ultimate load with corresponding deflections

\begin{tabular}{|c|c|c|c|c|}
\hline SLAB ID & $\begin{array}{c}\text { Pcr } \\
(\mathbf{k N})\end{array}$ & $\begin{array}{c}\mathbf{A}_{\mathbf{\alpha}} \\
(\mathbf{m m})\end{array}$ & $\mathbf{P u}(\mathbf{k N})$ & $\begin{array}{c}\mathbf{A}_{\mathbf{r}} \\
(\mathbf{m m})\end{array}$ \\
\hline M20/PT1 & 28.6 & 1.99 & 83.5 & 24.8 \\
\hline M20/PT2 & 43 & 2.2 & 121.7 & 14.45 \\
\hline M70/PT1 & 40.9 & 1.86 & 85.9 & 28.29 \\
\hline M70/PT2 & 37 & 2.48 & 126.4 & 15.02 \\
\hline
\end{tabular}

Table:4 Comparison of Ultimate load to Johanssen Yield Load

\begin{tabular}{|c|c|c|c|}
\hline SLAB ID & $\mathbf{P}_{\mathbf{u}(\mathbf{e x})}(\mathbf{k N})$ & $\mathbf{P}_{\mathbf{i}(\mathbf{c a l})}(\mathbf{k N})$ & $\mathbf{P}_{\mathbf{u}(\mathbf{e x})} / \mathbf{P}_{\mathbf{i}(\mathrm{cal})}$ \\
\hline $\mathrm{M} 20 / \mathrm{PT} 1$ & 83.5 & 70.79 & 1.18 \\
\hline $\mathrm{M} 20 / \mathrm{PT} 2$ & 121.7 & 136.08 & 0.89 \\
\hline $\mathrm{M} 70 / \mathrm{PT} 1$ & 85.9 & 74.57 & 1.15 \\
\hline $\mathrm{M} 70 / \mathrm{PT} 2$ & 126.4 & 158.05 & 0.80 \\
\hline
\end{tabular}

From table 3, it was noticed that the first crack load of NSC slabs were increased by $50.35 \%$ and HSC slabs decreased by $10.54 \%$ when reinforcement ratio increased from $0.34 \%$ to $0.79 \%$. However, the ultimate load for NSC slabs increase by $45.75 \%$ and HSC slabs increased by $47.15 \%$ as the reinforcement increased from $0.34 \%$ to $0.79 \%$. For $0.34 \%$ of reinforcement the first crack load increased by $43 \%$ and for $0.79 \%$ reinforcement it decreased by $16.21 \%$ as the grade of concrete increased. The deflection at first crack, for NSC slabs was increased by $10.55 \%$ and for HSC slabs it was increased by $33.3 \%$ with increase in reinforcement ratio from $0.34 \%$ to $0.79 \%$. thedeflections at ultimate load, for NSC slabs reduced to $71.62 \%$ and for HSC slabs it reduced to $88.35 \%$ when reinforcement ratio increased from $0.34 \%$ to $0.79 \%$. For $0.34 \%$ reinforcement ratio the deflection at first crack was reduced by $6.99 \%$ and for $0.79 \%$ reinforcement ratio it was seen to increase by $12.73 \%$ with increase in grade of concrete.
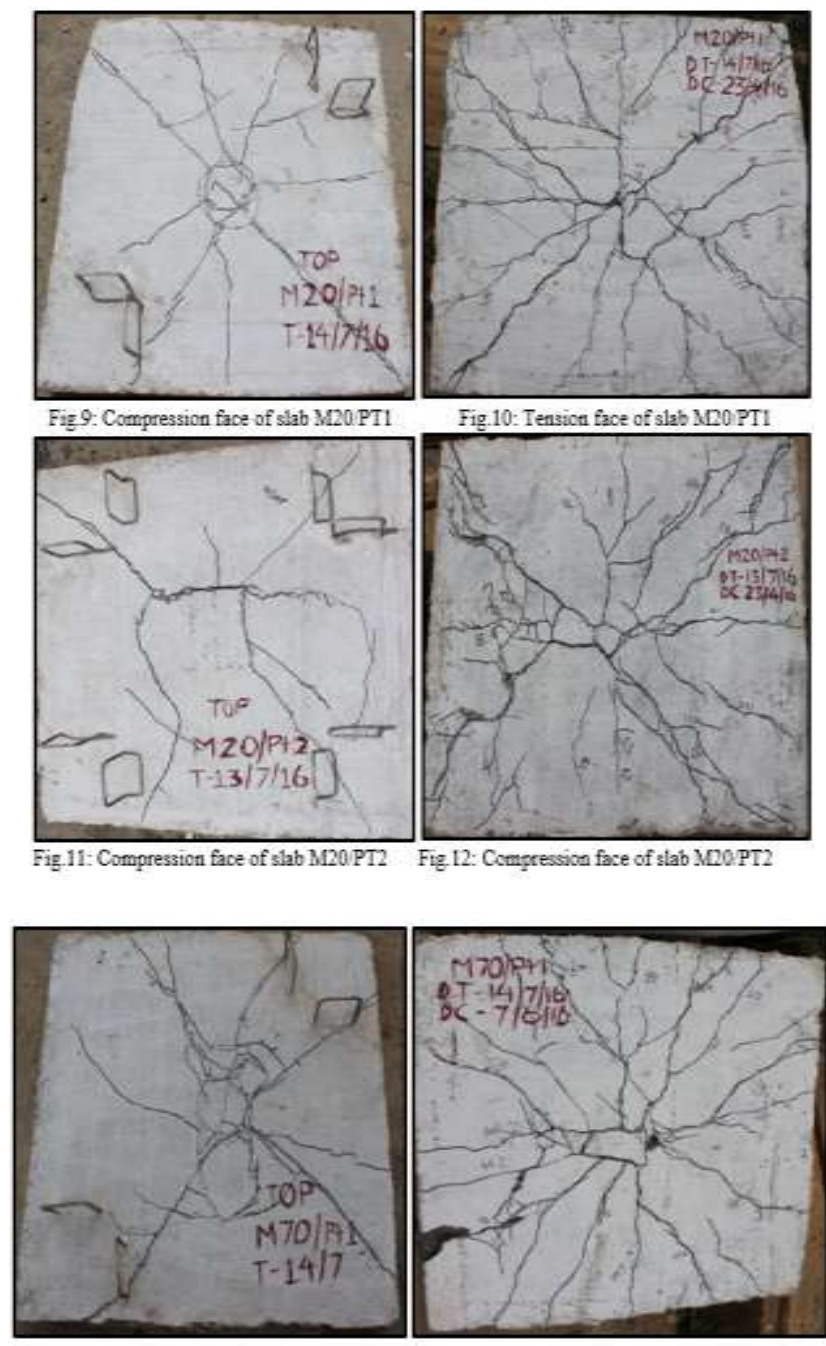

Fig.11: Compression face of slab M70PT1 Fig 12: Compression face of slab MnoPT1
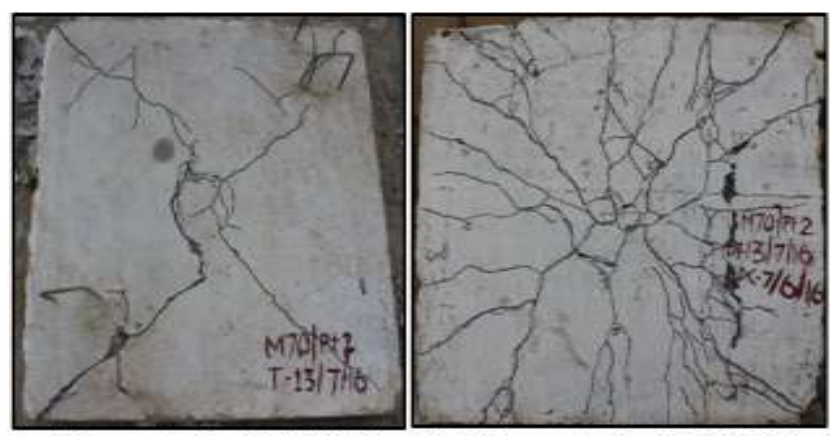

Fig.11: Comeressics face of slab M70PT2 


\subsection{Comparison of Ultimate Load with Johanssen}

\section{Yield Load}

From the table 4 it was observed that the ultimate load for NSC and HSC slab with $0.34 \%$ reinforcement was found to be $18 \%$ and $15 \%$ higher than Johanssen yield load respectively. However, in case of $0.79 \%$ reinforcement the ultimate load was reduced by $11 \%$ and $20 \%$ for NSC and HSC slabs respectively.

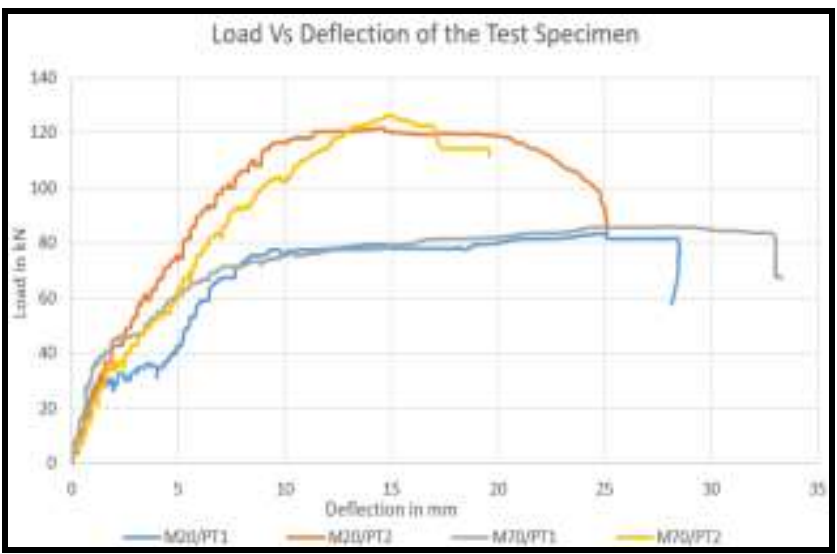

Fig. 6: Combined Load deflection curves of test specimen

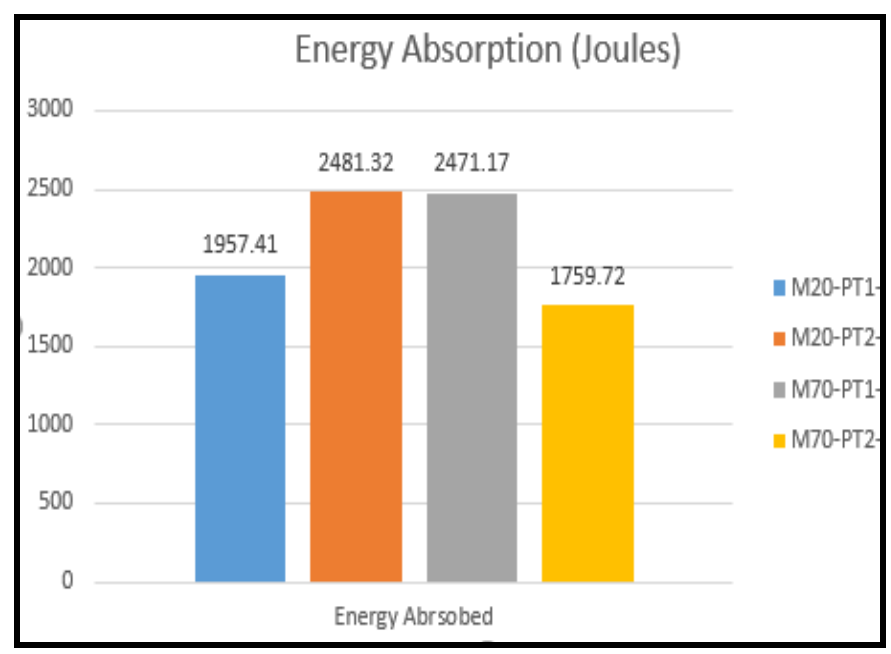

Fig.7: Energy absorption of Test Specimen

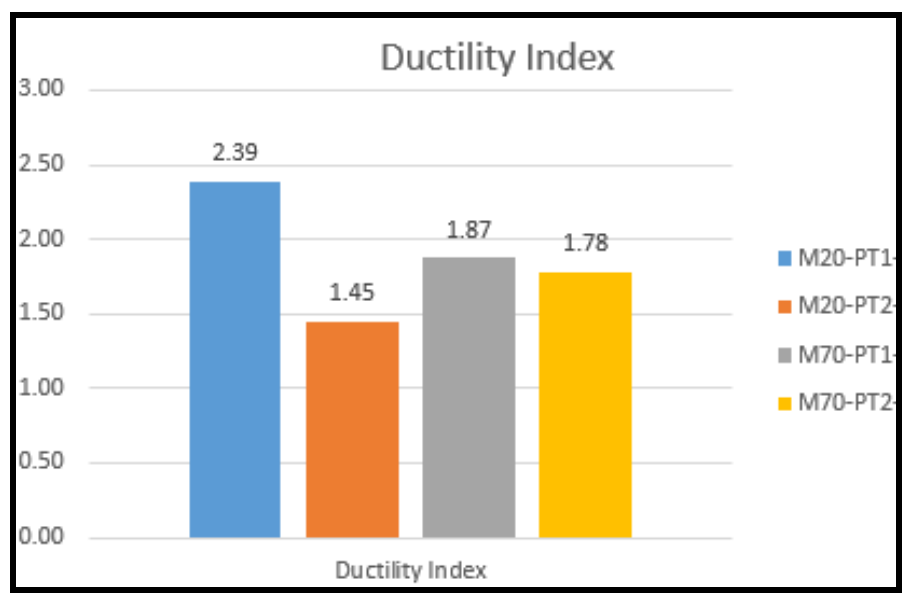

Fig. 8: Ductility Index of Test Specimen

\subsection{Load Deflection Behaviour}

The combined load deflection behaviour as shown in fig.6, it was observed that the maximum load was found to be more for higher percentage reinforcements regardless of the concrete grade. The deflections were found to be more in lower percentage of reinforcements. This is because as the percentage of reinforcement increases, the stiffness of the member increases. As the percentage of reinforcement increases the load carrying capacity was increased.

\subsection{Energy Absorption}

From the load deflection curves the energy absorption the area under the curve was calculated using trapezoidal formula and this was correlated to energy absorption of the slabs. This was graphically represented in form of a bar chart shown in Fig.7. From Fig 7 it was inferred that for $0.34 \%$ reinforcement ratio the energy absorption increased with increase in concrete grade whereas for $0.79 \%$ it decreased it is because of the combined effect of higher percentage of reinforcement and brittle nature of higher grade of concrete.

\subsection{Ductility Index}

From the load deflection curves the yield points were identified and the ductility index was computed as the ratio of deflection at ultimate to yield load point. The Ductility Index for the test specimen is shown in Fig.8, from this fig it was observed that for NSC slabs as the reinforcement increased from $0.34 \%$ to $0.79 \%$ the ductility index decreased by $64.83 \%$ and for HSC slabs it decreased by $5.05 \%$. For $0.34 \%$ reinforcement ratio as the concrete grade increased the ductility index reduced by $27.8 \%$ and for $0.79 \%$ reinforcement it increased by $22.76 \%$.

\section{CONCLUSION}

- As the reinforcement ratio increases the first crack load increases in case of NSC slabs however it decreased in case of HSC slabs.

- For $0.34 \%$ reinforcement the first crack load was increased and it decreased for $0.79 \%$ reinforcement as the grade of concrete increased.

- As the reinforcement ratio increases the ultimate load increases in case of both NSC and HSC slabs significantly.

- As the grade of concrete increases the ultimate load increases in case of both reinforcement ratios marginally.

- The deflections at first crack load was increased as the percentage of reinforcement was increased in case of both NSC and HSC slabs.

- As the grade of concrete as increased the deflections at first crack load for $0.34 \%$ reinforcement decreased whereas for $0.79 \%$ reinforcement increased.

- The deflections at ultimate load was reduced as the percentage of reinforcement increased in case of both NSC and HSC slabs. 
- As the grade of concrete increased deflections increased marginally for both reinforcement ratios.

- The increase in grade of concrete increased the energy absorption for $0.34 \%$ reinforcement and decreased for $0.79 \%$ reinforcement.

- The increase in reinforcement increased the energy absorption for NSC slabs and decreased for HSC slabs.

- The increase in percentage of reinforcement decreased the ductility index in both NSC and HSC slabs.

- As the grade of concrete was increased the ductility index reduced for $0.34 \%$ reinforcement and increased for $0.79 \%$ reinforcement.

- All the slabs were failed in flexure except the HSC slab with $0.79 \%$ reinforcement in which the punching shear failure was observed.

\section{REFERENCES}

[1]. Rakesh Kumar Sahu, S P Mishra (March 2015) "Exploring possibility of Developing High Strength Concrete using Locally Available Materials", International Journal of Advanced Engineering Research and Studies" IV/II/76-78

[2]. Sudarsana Rao Huchante, Shashidhar Chandupalle, Vaishali G Ghorpode and Venkata Reddy T C "Mix Design of High Performance Concrete Using Silica Fume and Superplasticizer" (March 2014) International Journal of Innovative Research in Science, Engineering and Technology (IJIRSET)Volume 3, Issue 3

[3]. N Banthia, S Mindess, A. Bentur and M Pigeon (1988) "Impact Testing of Concrete Using Drop-weight Impact Machine" Experimental mechanics Pp 63-69

[4]. Andreas Andersson, "Impact Loading on Concrete Slabs" (2014) Thesis submitted to KTH Architecture and Built Environment ISSN 1103-4289, Sweden

[5]. Micael Inacio, Antonio Ramos, Valter Lucio and Duarte Faria, "Punching of High Strength Concrete Flat SlabsExperimental Investigation" UNIC, Civil Engineering Department, Faculdade de Ciencias e Tecnologia, Universidade NOVA de Lisboa, 2859-516, Monte de Caparica, Portugal 